\title{
Radiographic appearance of bronchial carcinoid
}

\author{
R OBERT L. ALTMAN, W. EUGENE MILLER, DAVID T. CARR, \\ W. SPENCER PAYNE, and LEWIS B. WOOLNER
}

Mayo Clinic and Mayo Foundation, Rochester, Minnesota

\begin{abstract}
Altman, R. L., Miller, W. E., Carr, D. T., Payne, W. S., and Woolner, L. B. (1973). Thorax, 28, 433-434. Radiographic appearance of bronchial carcinoid. The chest radiographs of 67 patients with bronchial carcinoid were reviewed. Seven had negative radiographs. Fifty-five had single abnormalities, the common manifestations being collapse or pneumonitis (21 patients), a small peripheral mass (20 patients), and a hilar or perihilar mass (11 patients). Five patients had multiple abnormalities, the most common combination being a mass with evidence of bronchial obstruction such as collapse of the related segment or lobe. Comparison with other reports revealed a significant difference in the frequency of the various abnormalities, a difference probably due to chance variations in the locations and to the age of the tumours at the time of diagnosis.
\end{abstract}

The radiographic manifestations of the most common cell types of bronchogenic carcinoma have been described in four previous papers from our institution (Lehar et al., 1967 ; Byrd et al., $1968 \mathrm{a}, \mathrm{b}, \mathrm{c})$. This report is a study of the radiographic appearance of bronchial carcinoid.

\section{MATERIALS AND METHODS}

The records of the Mayo Clinic for 1959-68 were searched for cases of bronchial carcinoid. During these

\section{T A B LE I} \section{CLASSIFICATION OF RADIOGRAPHIC ABNORMALITIES IN} BRONCHIAL CARCINOID

\footnotetext{
Hilar involvement

1 Hilar prominence: slight enlargement of structures in hilar area without discrete mass

2 Hilar mass: discrete mass limited to hilar area

3 Perihilar mass: discrete mass limited to perihilar area with centre within $4.0 \mathrm{~cm}$ of the hilus

Pulmonary parenchymal involvement

1 Small mass: single mass $4.0 \mathrm{~cm}$ in diameter within substance of lung, not necessarily with a well-defined border

2 Large mass: single mass greater than $4.0 \mathrm{~cm}$ in diameter within substance of lung, not necessarily with a welldefined border

3 Apical mass: single mass of any size limited to apex of lung

4 Multiple masses: two or more masses of any diameter within substance of lung

5 Hypertranslucency: increased radiolucency of lung, lobe, or segment

6 Collapse: decrease in volume of lung, lobe, or segment

7 Consolidation: a homogeneous opacification of a lung, lobe, or segment, without decrease in volume

8 Pneumonitis: a non-homogeneous opacification with a hazy outline of a lung, lobe, or segment without decrease in volume

Intrathoracic extrapulmonary involvement

1 Mediastinal mass or widening: local or diffuse enlargement of the normal mediastinal shadow

ment of the normal mediastinal shadow

2 Chest wall: erosion or interruption in normal contours of chest wall structures or vertebrae

3 Pleural effusion

4 Hemidiaphragm elevation
}

10 years there were 71 such cases. The diagnosis was confirmed in every case by a review of the histological sections of the tumour. Stereoscopic chest radiographs were available for review for 67 of the 71 patients. In some cases, additional radiographs were available ; these included lateral films, tomograms, bronchograms, decubitus views, and, in a few cases, films made at an earlier examination illustrating the development of the tumour. All the films were used to classify the tumour according to the radiographic patterns of abnormalities listed in Table I.

\section{RESULTS}

The radiographs of seven patients showed no abnormality, even in retrospect. Of the remaining 60 patients who had radiographs, 55 had a single radiographic abnormality and five had a total of 11 radiographic abnormalities (Table II). The most common single abnormalities were a small peripheral mass (20 cases) and collapse of a lobe or segment of a lobe (19 cases). These were also the most common abnormalities in cases with multiple radiographic abnormalities. Perihilar and hilar masses were the next most common abnormalities in both groups.

\section{DISCUSSION}

Comparison of our data with those in other reports is difficult because of different classifications of the radiographic abnormalities in various papers. Furthermore, one cannot be certain that only bronchial carcinoids are included in some of the reports. A brief comment, however, about some of the data in the literature seems worthwhile. For example, in 1953 Good and Harrington 
T A B L E I I

ABNORMAL RADIOGRAPHIC PATTERNS IN 67 PATIENTS WITH BRONCHIAL CARCINOID ${ }^{1}$

\begin{tabular}{l|cc}
\multicolumn{1}{c|}{ Abnormality } & Single & Multiple \\
\hline Hilar & 1 & 0 \\
Hilar prominence & 5 & 2 \\
Hilar mass & 6 & 1 \\
Perihilar mass & 20 & 3 \\
Pulmonary parenchymal involvement & 0 & 0 \\
Small mass & 0 & 0 \\
Large mass & 1 & 0 \\
Apical mass & 1 & 0 \\
Multiple masses & 19 & 4 \\
Hypertranslucency & 0 & 0 \\
Collapse & 2 & 0 \\
Consolidation & 0 & 0 \\
Pneumonitis & 0 & 0 \\
Intrathoracic extrapulmonary involvement & 0 & 0 \\
Mediastinal mass or widening & 0 & 1 \\
Chest wall & 55 & $11^{2}$ \\
Pleural effusion & & \\
\hline Hemidiaphragm elevation & & 0 \\
\hline Total & & \\
\hline
\end{tabular}

${ }^{1}$ Seven patients had normal findings on chest radiographs.

${ }^{2} \mathrm{~A}$ total of 11 abnormalities in five patients.

reported on 100 cases of bronchial adenoma from the Mayo Clinic records. Seventy-seven of these had radiographic evidence of bronchial obstruction and only 23 had evidence of a mass in the lung.

Baldwin and Grimes (1967) studied 56 patients who had respiratory tract adenomas and who were seen between 1920 and 1965 . Only 13 patients presented with solitary peripheral masses, and 15 had a hilar mass or mediastinal widening. The remaining 28 patients had radiographs that 'were either negative or showed only varying degrees of pneumonia, atelectasis, emphysema, or segmental abscesses'.

Giustra and Stassa (1969) reported on the radiographic findings in 84 patients with bronchial adenomas: six had negative radiographs, 24 had a peripheral nodule or mass, 14 had a hilar mass alone, 12 had a hilar mass with an infiltrate or atelectasis, 27 had an infiltrate or atelectasis without a demonstrable mass, and one had emphysema.

Only seven of the 33 patients reported by O'Grady, McDivitt, Holman, and Moore (1970) presented with a solitary peripheral mass ; 11 had an infiltrate or atelectasis, and eight more had these changes with a hilar mass. Two of the remaining seven had negative radiographs.

Evidence of bronchial obstruction such as atelectasis or pneumonitis was also the most common abnormality in the series of 35 patients reported by Donahue, Weichert, and Ochsner
(1968) ; 16 patients had such a manifestation of the disease. Six had a parenchymal mass, and 120 had a hilar mass. The remaining patient had a음 negative radiograph.

Meffert and Lindskog (1970) reported that only市 12 of their 35 patients had a mass or masses ong radiographic examination, whereas 23 had atelectasis or pneumonitis with or without a mass.

These differences may be attributed at least in $\vec{\omega}$ part to chance variations in location of theo tumours, the frequency of routine chest radio- $\vec{x}$ graphs among the population from which the patients were derived, and the age of the tumouro at the time of diagnosis. If the tumour arises in the hilar or perihilar region, it may be detectedw as a solitary mass or the diagnosis may not beo made until some manifestation of bronchial obstruction develops. If the mass is peripheral, it should be detectable as a small asymptomatic circumscribed nodule in the lung. However, many $\vec{\circ}$ persons do not have routine chest radiographs, and such tumours may not be discovered untif they have grown large enough to cause symptoms

\section{REFERENCES}

Baldwin, J. N., and Grimes, O. F. (1967). Bronchial adeno@ mas. Surgery Gynecology and Obstetrics, 124, 813.

Byrd, R. B., Miller, W. E., Carr, D. T., Payne, W. S., anç Woolner, L. B. (1968a). The roentgenographic appearance of squamous cell carcinoma of the bronchus Mayo Clinic Proceedings, 43, 327. (1968b). The roentgenographif appearance of large cell carcinoma of the bronchuse Mayo Clinic Proceedings, 43, 333.

(1968c). The roentgenographie appearance of small cell carcinoma of the bronchus Mayo Clinic Proceedings, 43, 337.

Donahue, J. K., Weichert, R. F., and Ochsner, J. L. (1968) Bronchial adenoma. Annals of Surgery, 167, 873.

Giustra, P. E., and Stassa, G. (1969). The multiple presenta음 tions of bronchial adenomas. Radiology, 93, 1013.

Good, C. A., and Harrington, S. W. (1953). Asymptomati bronchial adenoma. Proceedings of the Mayo Clinic, 280 577.

Lehar, T. J., Carr, D. T., Miller, W. E., Payne, W. S., and Woolner, L. B. (1967). Roentgenographic appearance of bronchogenic adenocarcinoma. American Review og Respiratory Diseases, 96, 245.

Meffert, W. G., and Lindskog, G. E. (1970). Bronchiab adenoma. Journal of Thoracic and Cardiovascular Sur gery, 59, 588.

O'Grady, W. P., McDivitt, R. W., Holman, C. W., and Moore, S. W. (1970). Bronchial adenomas. Archives of Surgery, 101, 558. 